\title{
A COMPARISON OF REINFORCED CONCRETE AND REINFORCED HPFRCC BEAM RESPONSE TO DIFFERENT CYCLIC DEFORMATION HISTORIES ${ }^{1}$
}

\author{
TIMOTHY E. FRANK* ${ }^{*}$ MICHAEL D. LEPECH ${ }^{\dagger}$ AND SARAH L. BILLINGTON ${ }^{\dagger \dagger}$
}

\author{
Stanford University \\ Stanford, CA USA \\ e-mail: tefrank@stanford.edu \\ ${ }^{\dagger}$ Stanford University \\ Stanford, CA USA \\ e-mail: mlepech@stanford.edu \\ ${ }^{\dagger}$ Stanford University \\ Stanford, CA USA \\ e-mail: billington@stanford.edu
}

${ }^{1}$ The views expressed in this article are those of the authors and do not reflect the official policy or position of the United States Air Force, Department of Defense, or the U.S. Government.

Key words: Reinforced Concrete, Reinforced HPFRCC, Cyclic Loading, Deformation History

\begin{abstract}
High performance fiber-reinforced cement composites (HPFRCCs) have been designed to exhibit high tensile strength and ductility compared to traditional concrete. HPFRCCs have also shown improved damage tolerance in compression. When reinforced with steel, HPFRCC components have been proposed for enhanced seismic resistance in structural applications.

Because of the uncertainty associated with ground motions, determining an appropriate cyclic deformation history for seismic testing of structural components is a challenge. Different cyclic deformation histories have resulted in different cracking patterns in previous HPFRCC component tests. Several different cyclic loading protocols have been used in previous studies, but the deformation history itself has rarely been treated as a test variable.

Two reinforced HPFRCC beams and two reference specimens made of reinforced concrete were tested under two different cyclic loading protocols. Cracking patterns, strain in the steel reinforcement, and hysteresis behavior were monitored through failure. The reinforced HPFRCC beams responded differently to different deformation histories than the reinforced concrete beams in terms of ductility and the amount of energy dissipated. Results from this study will contribute to a better understanding of reinforced HPFRCC component behavior under various cyclic deformation histories.
\end{abstract}

\section{INTRODUCTION}

\subsection{HPFRCCs}

High performance fiber-reinforced cement composites (HPFRCCs) are a class of cement based materials that has been developed and studied for over three decades. HPFRCCs have many similar constituents to traditional concrete, but also contain short, randomly distributed fibers.

The definitive characteristic of HPFRCC material behavior that sets it apart from 
concrete and other fiber reinforced cement composites is its ability to form multiple, steady-state cracks under uniaxial tension. On a mesoscale, multiple cracking allows an HPFRCC component to gain strength beyond the formation of the first crack, a phenomenon referred to as pseudo-strain hardening [described in, e.g., 1]. Depending on the specimen size, shape, mix design, and applied strain rate, HPFRCC specimens have achieved specimen strains between $0.25 \%$ and $5 \%$ under uniaxial tension before tension-softening [2-5].

\subsection{Research motivation}

Quasi-static cyclic tests on structural components have been used to gain a better understanding of structural response to seismic loads. As HPFRCC with embedded steel reinforcement has been proposed and implemented in structural applications [e.g., 78 and several others since], laboratory experimentation under cyclic loads can be a valuable tool to understand the material's limits and capabilities, and to ultimately make recommendations for design codes.

Cost and time typically limit laboratory testing to a small number of specimens. With a limited test regimen, the choice of deformation history to impose on each specimen is important. The seismic demand on a structure depends on many variables including for example, ground motion characteristics, soil properties, inertial mass, and structural period. Therefore, selecting a single deformation history will "always be a compromise, but one that should be conservative for most practical cases," [8].

Many researchers have used a deformation history that begins with small, elastic cycles. Cyclic amplitude is increased every one to three cycles. These cycles are imposed on the component in a deformation-controlled fashion until a predetermined failure criterion is reached.

An understanding of reinforced HPFRCC component behavior under a deformation history wherein the cyclic amplitude of each step does not always monotonically increase is of interest for several reasons. First, cracking of a reinforced HPFRCC infill panel subjected to a recorded ground motion was significantly different than cracking of a similar component subjected to a monotonically increasing cyclic deformation history [9]. In a separate study, the authors noticed differences in cracking and strain accumulation in the steel reinforcement when comparing reinforced HPFRCC specimen behavior under various deformation histories [10].

Second, structural components made from traditional reinforced concrete have been found to behave differently under different deformation histories [11-13]. Strength and stiffness deterioration as well as ultimate ductility varied depending on the deformation history applied.

Third, initial deformation pulses from ground motions are possible, and simulations using recorded ground motions suggest they can generate story drifts of at least $7 \%$ in a structure [14]. The effect of initial deformation pulses on a reinforced HPFRCC component may be different than on a reinforced concrete component because of the nature of the HPFRCC matrix itself. Initial pulses imposed on an HPFRCC component could form a dominant crack with fiber pullout or rupture early in the deformation history, and thus fundamentally change the composite material's behavior thereafter. Typical material characteristics of reinforced HPFRCCs such as strong bond to steel reinforcement [15] and strain hardening of the reinforcement at low levels of specimen strain [16] could lead to different behavior when subjected to a deformation history with initial pulses than reinforced concrete would exhibit.

To address some of these gaps in understanding, direct comparisons of reinforced concrete specimens have been made to reinforced HPFRCC specimens in the past. Increases in energy dissipated, strength, and ductility as well as a reduction in transverse steel required were noted in reinforced HPFRCC beams relative to reinforced concrete beams [17-18]. In another study, the authors noted a difference in failure mode between reinforced HPFRCC and reinforced concrete columns, and a higher strain accumulation rate 
in bars embedded in the HPFRCC [19]. To date, however, there has been no study examining the differences between reinforced concrete and reinforced HPFRCC beams treating deformation history as an experimental variable.

\section{MATERIALS AND METHODS}

\subsection{Mixture designs and casting}

Two reinforced concrete specimens were cast and tested in this study. The concrete was provided by a local ready-mix plant per the mixture design shown in Table 1 and delivered to the site. The concrete for the two reinforced concrete specimens came from the same batch.

Table 1: Concrete mixture design (per cubic meter)

\begin{tabular}{cc}
\hline Constituent & Mass (kg) \\
\hline Type II/V Portland Cement & 473 \\
\hline $1 \mathrm{~cm}$ Pea Gravel & 751 \\
\hline Sand & 828 \\
\hline Water & 144 \\
\hline
\end{tabular}

Two reinforced HPFRCC specimens were cast and tested in this study. The type of HPFRCC used was Engineered Cementitious Composite (ECC). Mixture proportions of the ECC are shown in Table 2. The silica sand had a $0.10 \mathrm{~mm}$ effective size. The polyvinyl alcohol (PVA) fibers were supplied by Kuraray Co. Ltd. and represented $2 \%$ of the composite by volume. Fibers were $8 \mathrm{~mm}$ long and had a 40 $\mu \mathrm{m}$ diameter. The ECC for each reinforced ECC specimen was made on site from separate batches made on separate days.

Table 2: ECC mixture design (per cubic meter)

\begin{tabular}{cc}
\hline Constituent & Mass (kg) \\
\hline Type II/V Portland Cement & 547 \\
\hline Class F Fly Ash & 656 \\
\hline Silica Sand & 438 \\
\hline Water & 312 \\
\hline PVA Fibers & 26.0 \\
\hline High Range Water Reducer & 2.74 \\
\hline Viscosity Modifying Admixture & 0.613 \\
\hline
\end{tabular}

All four specimens were moist cured for seven days and then allowed to cure at room temperature until being tested. The reinforced
ECC specimens were tested on day $28 \pm 2$ days. To reduce the difference in estimated compressive strength between concrete and ECC, the reinforced concrete specimens were allowed to cure longer, and were tested on day $56 \pm 2$ days. All four specimens were reinforced with deformed mild steel bars with a $13 \mathrm{~mm}$ diameter. Smooth, $3.2 \mathrm{~mm}$ diameter steel wire was used for transverse reinforcement.

\subsection{Specimen geometry and instrumentation}

The dimensions of all four specimens were nominally identical. Specimen dimensions and the test set up are shown in Figure 1. The vertical beam had a cross section of $165 \mathrm{~mm}$ by $203 \mathrm{~mm}$. One bar embedded in each corner resulted in a $0.95 \%$ reinforcement ratio in flexure. Clear cover to the longitudinal bars was $32 \mathrm{~mm}$ on all sides.

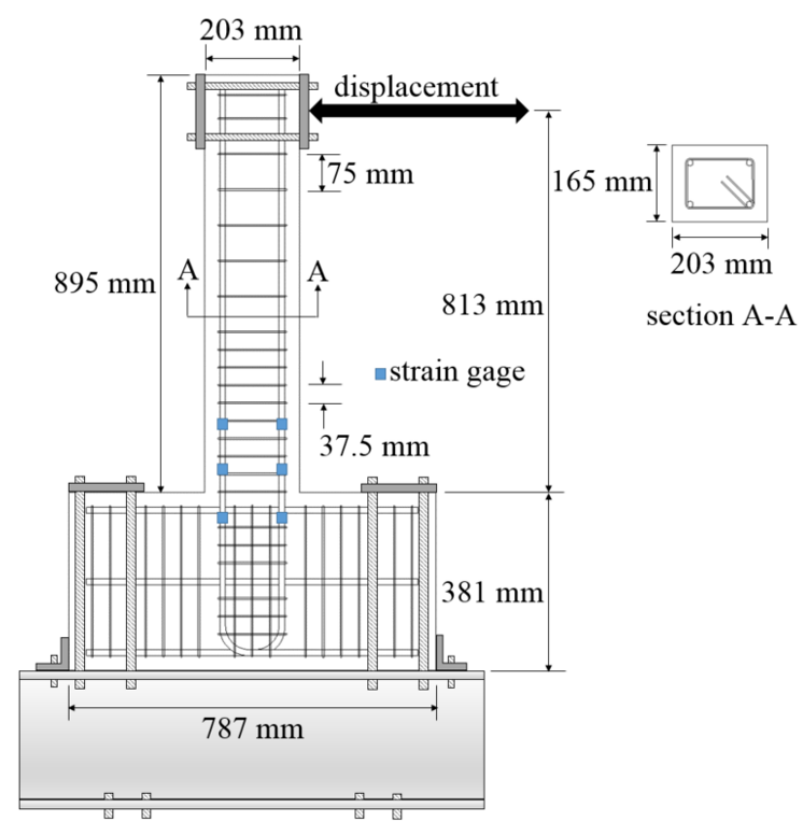

Figure 1: Specimen dimensions and test setup

The enlarged base had a cross section of 229 $\mathrm{mm}$ by $381 \mathrm{~mm}$. A total of six, $13 \mathrm{~mm}$ horizontal bars reinforced the enlarged base.

Transverse reinforcement was designed as seismic detailing per ACI 318-14 [20]. Stirrups were spaced at $37.5 \mathrm{~mm}$ throughout the enlarged base and $342 \mathrm{~mm}$ into the beam. The remainder of the beam stirrups were spaced at $75 \mathrm{~mm}$.

Two of the four longitudinal reinforcing bars 
in each specimen were instrumented with three strain gages. One gage was located within the joint $5 \mathrm{~cm}$ below the joint face, and two were within the beam, one $5 \mathrm{~cm}$ above the joint face, and one $15 \mathrm{~cm}$ above the joint face. Three string potentiometers placed at third points along the length of the beam recorded displacement. Though not reported herein, deflected shape and specimen strain were monitored through a series of $6 \mathrm{~mm}$ dots painted on the surface of the specimens for use in digital image postprocessing. Resistive force was recorded by a $50 \mathrm{kN}$ load cell attached to the hydraulic actuator that displaced the specimen.

\subsection{Testing and deformation histories}

The enlarged base of each specimen was bolted to a wide flange section, which was fixed to the strong floor (Figure 1). Bending out of plane was restrained by bracing (not shown). One end of the hydraulic actuator was attached to a test frame and the other to the specimen by bolts and steel plates. The actuator moved 4.23 $x 10^{-2} \mathrm{~mm} / \mathrm{s}$, and cyclic reversals were controlled by the string potentiometer at the same level as the actuator. Axial load was not applied to any specimen.

The naming convention of each specimen indicates the material (either $\mathrm{RC}$ for reinforced concrete or ECC for reinforced ECC), the reinforcement ratio $(0.95 \%)$, and a descriptor indicating the applied cyclic deformation history. Two deformation histories were used in this study (Figure 2); one each applied to a specimen of each material.

The first deformation history, proposed by the Federal Emergency Management Agency (FEMA), is similar to many commonly used in previous research. The FEMA 461 deformation history consists of increasing amplitude steps with two cycles per step [21]. The first step was $0.15 \%$ drift where drift was measured as beam tip displacement divided by the $813 \mathrm{~mm}$ beam length. Each subsequent step was $40 \%$ larger than the previous (Figure 2a). The first few steps were not expected to yield the steel reinforcement.

The other deformation history began with two initial pulses to $7 \%$ drift followed by the
FEMA 461 deformation history (Figure 2b). Initial pulses of $7 \%$ drift were selected with the intention to cause total softening in the ECC material. The naming convention used in this study refers to the FEMA 461 deformation history as "CF," for "Cyclic FEMA." The deformation history with $7 \%$ initial pulses is referred to as "C7PF" for "Cyclic with $\underline{7} \%$ Pulses, then FEMA."
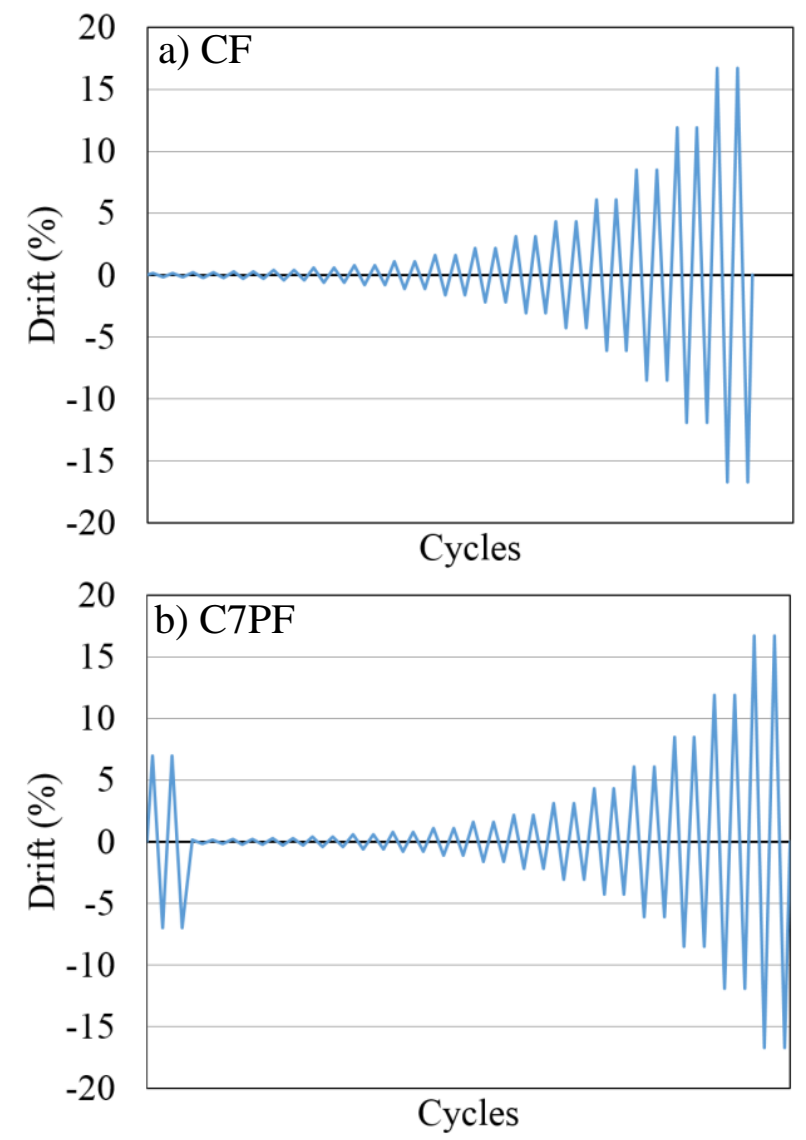

Figure 2: Testing deformation histories a) Cyclic FEMA 461 and b) Cyclic FEMA 461 with 7\% initial pulses

Testing continued until one of two failure criteria were met: either one of the steel reinforcing bars fractured or the strength at the peak of an inelastic excursion was less than $75 \%$ of yield strength (about $60 \%$ to $75 \%$ of ultimate strength).

\section{RESULTS}

\subsection{Material properties}

Concrete from the same batch as the test specimens was used to cast $100 \mathrm{~mm} \times 200 \mathrm{~mm}$ 
cylinders and $80 \mathrm{~mm} \times 80 \mathrm{~mm} \times 305 \mathrm{~mm}$ beams. Compression strength of the concrete was $42 \pm$ 3.3 MPa based on tests of four cylinders tested at $56 \pm 2$ days, the same age as the test specimens. The modulus of rupture of the concrete was $5.5 \pm 0.52 \mathrm{MPa}$ based on four beams tested in third point bending tested at 56 \pm 2 days.

ECC was also tested in compression and third point bending. In compression, ECC achieved a strength of $47 \pm 3.7 \mathrm{MPa}$ based on tests of four cylinders. The modulus of rupture of the ECC was $10 \pm 1.4 \mathrm{MPa}$ based on third point bending tests of four beams tested at $28 \pm$ 2 days, the same age as the test specimens.

Yield stress $\left(f_{y}\right)$, ultimate stress $\left(f_{u}\right)$, and strain at ultimate stress $\left(\varepsilon_{\mathrm{u}}\right)$ for the steel used as transverse and longitudinal reinforcement are shown in Table 3 based on the average of two samples each.

Table 3: Steel reinforcement bar properties

\begin{tabular}{cccc}
\hline Bar dia. $(\mathrm{mm})$ & $\mathrm{f}_{\mathrm{y}}(\mathrm{MPa})$ & $\mathrm{f}_{\mathrm{u}}(\mathrm{MPa})$ & $\varepsilon_{\mathrm{u}}(\%)$ \\
\hline 3.2 & 690 & 820 & 13 \\
\hline 13 & 455 & 675 & 16 \\
\hline
\end{tabular}

\subsection{Cracking}

The cracking pattern in RC-0.95-CF began as horizontal flexural cracks until about $3.1 \%$ drift, when cracks inclined at approximately 45 degrees and formed an X-shaped pattern of cracking through the specimen's core. The same X-shaped pattern of cracking occurred in RC-0.95-C7PF, but formed during the two initial pulses.

Table 4 presents various cracking observations from the two reinforced concrete specimens. There were many similarities across the two specimens. Almost all cracks that formed became full-depth cracks, meaning they could be traced from one side of the beam to the other. The cracks within the reinforced concrete specimens were all easily visible by the naked eye. A drift of $6.1 \%$ (within the FEMA 461 portion for those specimens subjected to the C7PF deformation history) was chosen as a point of comparison between specimens. The difference between the widest and narrowest crack in the reinforced concrete specimens was roughly one order of magnitude at $6.1 \%$ drift.

Table 4: Cracking observations in reinforced concrete specimens

\begin{tabular}{lcc}
\hline Observed response & CF & C7PF \\
\hline $\begin{array}{l}\text { Drift at dominant flexural } \\
\text { crack }{ }^{*} \text { formation, } \%\end{array}$ & 0.81 & $1.1^{\dagger}$ \\
\hline $\begin{array}{c}\text { Drift at major splitting } \\
\text { crack }{ }^{*} \text { formation, } \%\end{array}$ & 4.3 & $4.0^{\dagger}$ \\
\hline $\begin{array}{l}\text { Avg. no. flexural cracks } \\
\text { per side }\end{array}$ & 7 & 8 \\
\hline $\begin{array}{l}\text { No. full-depth cracks } \\
\text { Residual splitting crack } \\
\text { length, cm }\end{array}$ & 6 & 8 \\
\hline $\begin{array}{l}\text { Max. flexural crack width } \\
\text { at 6.1\% drift, mm }\end{array}$ & 2.3 & 1.9 \\
\hline $\begin{array}{l}\text { Max. splitting crack } \\
\text { width at 6.1\% drift, mm }\end{array}$ & 0.2 & 0.4 \\
rack width exceeding 0.1 mm \\
ccurred during the first initial pulse
\end{tabular}

Consistent with previous tests of reinforced ECC flexural members [17, 22], cracking in both reinforced ECC specimens consisted of horizontal flexural cracks with no diagonal cracks. Table 5 presents various cracking observations from the two reinforced ECC specimens. There were many similarities between cracking in the two reinforced ECC specimens such as drift at dominant flexural crack formation, number of flexural cracks, number of full-depth flexural cracks, and residual splitting crack length.

Cracking was different between the reinforced concrete and reinforced ECC specimens (Table 4 and Table 5). In general, a dominant flexural crack formed at about twice the drift in reinforced ECC (2.2\% drift) than reinforced concrete specimens $(0.81 \%$ or $1.1 \%$ drift). Dominant flexural crack formation indicated the start of matrix softening when fibers began to pull out of the matrix, and occurred near the base of the beam. At drifts beyond dominant flexural crack formation in the reinforced ECC specimens, specimen strain concentrated at the location of the crack.

There were about twice as many flexural cracks in reinforced ECC than reinforced concrete specimens, but only about $25 \%$ to $27 \%$ extended through the full depth of the 
reinforced ECC whereas $87 \%$ to $100 \%$ extended through the full depth of the reinforced concrete. Flexural crack widths in the ECC remained less than or equal to $0.1 \mathrm{~mm}$ throughout testing except for the dominant crack. Increases in cyclic amplitude at each step were accommodated by increases in the width of the dominant crack in the reinforced ECC specimens. The dominant crack width in the reinforced ECC specimens measured at $6.1 \%$ drift was about 2.5 times as large as the largest crack width in the reinforced concrete specimens. Average residual splitting crack lengths in reinforced ECC specimens $(12 \mathrm{~mm})$ were about half as long as those in reinforced concrete specimens $(25 \mathrm{~mm})$.

Table 5: Cracking observations in reinforced ECC specimens

\begin{tabular}{ccc}
\hline Observed response & CF & C7PF \\
\hline $\begin{array}{c}\text { Drift at dominant flexural } \\
\text { crack }{ }^{*} \text { formation, } \%\end{array}$ & 2.2 & $2.2^{\dagger}$ \\
\hline $\begin{array}{c}\text { Drift at major splitting } \\
\text { crack }{ }^{*} \text { formation, } \%\end{array}$ & 3.1 & $7.0^{\dagger}$ \\
\hline $\begin{array}{c}\text { Avg. no. flexural cracks } \\
\text { per side }\end{array}$ & 15 & 16 \\
\hline No. full-depth cracks & 4 & 4 \\
\hline $\begin{array}{c}\text { Residual splitting crack } \\
\text { length, cm }\end{array}$ & 13 & 11 \\
\hline $\begin{array}{c}\text { Max. flexural crack width } \\
\text { at } 6.1 \% \text { drift, mm }\end{array}$ & 5.5 & 6.6 \\
\hline $\begin{array}{c}\text { Max. splitting crack width } \\
\text { at } 6.1 \% \text { drift, mm }\end{array}$ & 0.5 & 0.3 \\
$\begin{array}{c}\text { crack width exceeding } 0.1 \text { mm } \\
\text { occurred during the first initial pulse }\end{array}$ & \\
\hline
\end{tabular}

\subsection{Reinforcement strain}

Strain in the steel reinforcement localized and accumulated differently between specimens of different material and different deformation history. Figure 3 shows plots of reinforcement strain versus specimen drift for each specimen through the completion of the $4.3 \%$ drift cycles. The strain plotted is that measured by the strain gage located $5 \mathrm{~cm}$ into the joint on the side of the specimen that went into tension first. The beginning of the first $0.15 \%$ drift cycle (after the conclusion of the two initial pulses for those specimens subjected to the C7PF deformation history) and the end of the second $4.3 \%$ drift cycle are indicated. The strain gage in ECC-0.95-C7PF failed during the first excursion; Figure $3 \mathrm{~d}$ shows all data that was recorded.

Steel reinforcement strain was compared between materials when specimens were subjected to the CF deformation history. When comparing Figure $3 \mathrm{a}$ to Figure 3c, reinforced concrete specimens had lower values of reinforcement strain at a given drift than reinforced ECC specimens. Less reinforcement strain in the reinforced concrete can be attributed to the wider flexural cracks and longer splitting cracks that developed in the concrete than the ECC. These strain results are in agreement with previous researchers' observation of reinforcement strain wherein the cracking behavior of concrete led to longer unbonded lengths in reinforced concrete specimens than reinforced ECC specimens under uniaxial tension [16]. The authors noted that the longer unbonded lengths facilitated specimen strain to be distributed over longer lengths of the steel reinforcement, and thus, the reinforcement strain at the critical section was lower in reinforced concrete than in reinforced ECC specimens [16].

Reinforcement strain at the end of the $4.3 \%$ drift step between the two reinforced concrete specimens were within $7 \%$ of eachother. No additional strain accumulated between the start of the $0.15 \%$ drift step and the end of the $4.3 \%$ drift step in RC-0.95-C7PF, however (Figure 3b). The lack of strain accumulation in the reinforcement when exposed to initial pulses is attributed to splitting cracks, slip, and bond deterioration that is expected to have occurred during the initial pulses. 

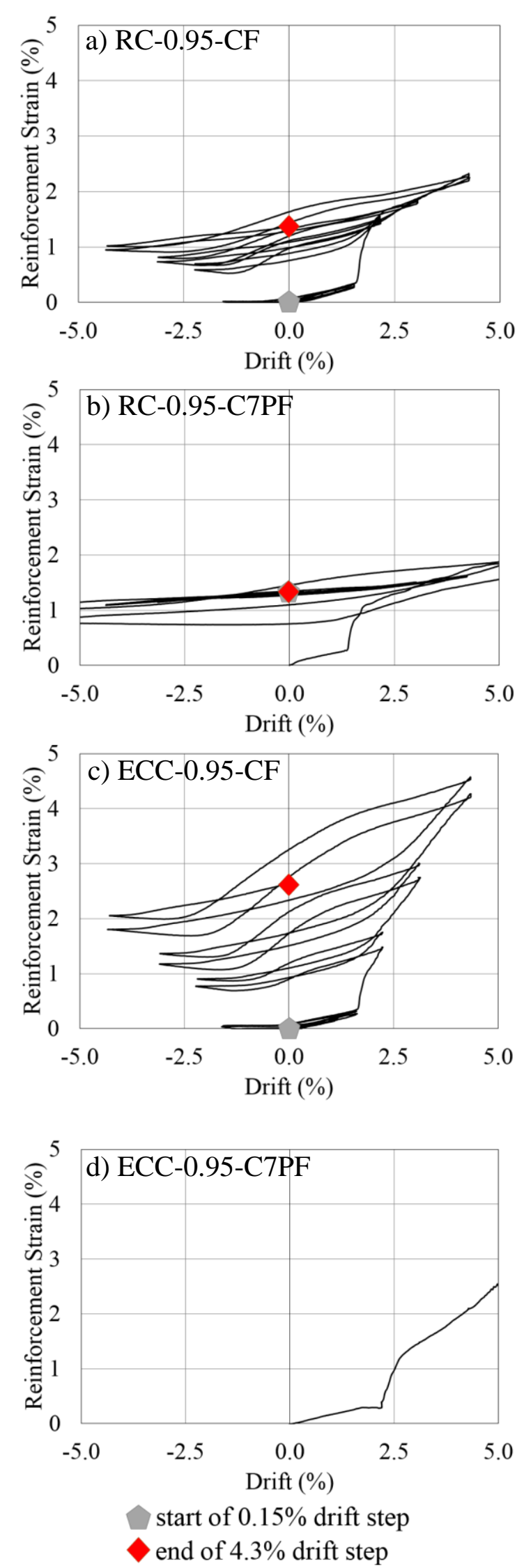

Figure 3: Reinforcement strain versus drift in a) RC0.95-CF, b) RC-0.95-C7PF, c) ECC-0.95-CF, and d) ECC-0.95-C7PF

\subsection{Hysteresis behavior}

Figure 4 shows the hysteretic response of the four specimens. Additionally, the point in the deformation history when splitting, crushing, and spalling was first observed on both sides of each specimen, as applicable, is shown. For the hysteretic envelope of reinforced concrete specimens, the strength gradually rose at a rate of 0.68 to $2.1 \mathrm{MPa}$ per percent drift between the drift at specimen yield and the drift at peak strength. Post-peak strength of both reinforced concrete specimens reduced through failure due to matrix degradation. The hysteretic envelope of reinforced ECC specimens, however, was characterized by a gradual reduction in strength at a rate of 0.20 to $0.60 \mathrm{MPa}$ per percent drift between the drift at specimen yield and the drift at specimen failure. Both reinforced ECC specimens failed due to bar fracture.

The difference in peak specimen strength (28 to $30 \mathrm{MPa}$ for reinforced concrete specimens and 30 to $32 \mathrm{MPa}$ for reinforced ECC specimens) was a result of the differences in tension and compression properties between the concrete and ECC. The point along the deformation history when peak strength was achieved, however, was also different between reinforced concrete and reinforced ECC specimens. RC-0.95-CF achieved peak strength during the $8.5 \%$ drift cycles, whereas RC-0.95$\mathrm{C} 7 \mathrm{PF}$ achieved peak strength at $4 \%$ drift during the first excursion as the matrix material on the compression side of the specimen was undamaged. Peak strength in the hysteretic envelope of both reinforced ECC specimens was achieved near $2 \%$ drift. The high strains that developed in the steel reinforcement led to strain hardening of the steel. This strain hardening coupled with the high damage tolerance of ECC, as indicated by the lack of significant crushing and spalling observed, facilitated the peak strength achieved by the reinforced ECC specimens at relatively low levels of drift.

Previous research noted reductions in strength and stiffness during excursions that followed, but were of lower amplitude than previous ones [11]. As expected, this phenomenon was observed during testing of 
both the reinforced concrete and reinforced ECC specimens subjected to the C7PF deformation history.

The hysteresis plots of reinforced concrete specimens show more pinching and lower reloading stiffness than those of reinforced ECC. The presence of the initial pulses generated more pinching in both reinforced concrete and reinforced ECC specimens when compared to respective specimens subjected to the CF deformation history due to the increased lateral translation caused by matrix damage and bar elongation generated during the initial pulses

When comparing the overall matrix behavior of the reinforced concrete (Figures $4 a-b$ ) to the reinforced ECC (Figure 4c-d) specimens, reinforced concrete specimens more often underwent crushing and spalling. This observation is consistent with previous research highlighting the high damage tolerance of ECC [e.g., 23].

Splitting cracks formed in each specimen, regardless of material and deformation history, at roughly the same drift, on average. There was more variability in drift at which splitting cracks formed in the reinforced ECC specimens than reinforced concrete specimens, however.

In reinforced concrete specimens, the progression of crushing to spalling to failure was evident. In reinforced ECC specimens, however, little about the cracking or hysteretic behavior indicated imminent failure because failure was due to fracture of the steel reinforcement. Crushing and spalling occurred in ECC-0.95-C7PF, but was limited when compared to the reinforced concrete specimens.
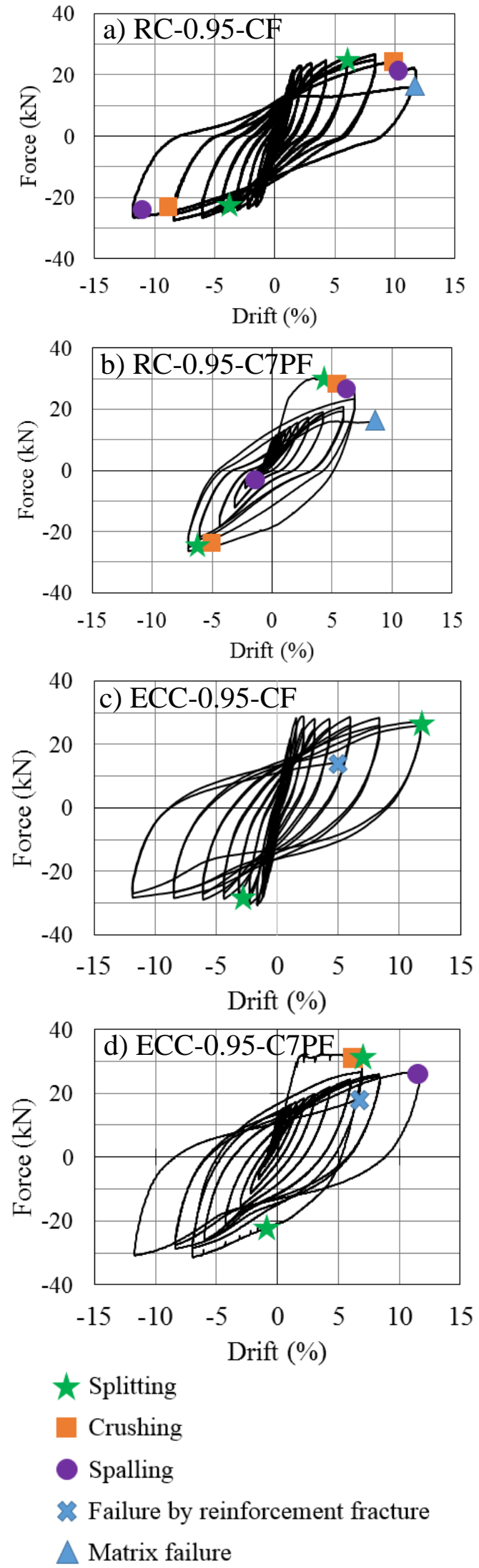

Figure 4: Hysteretic force versus drift plots for a) RC0.95-CF, b) RC-0.95-C7PF, c) ECC-0.95-CF, and d) ECC-0.95-C7PF 


\section{DISCUSSION}

\subsection{Impact of deformation history on specimen ductility}

Ductility is perhaps the most critical characteristic of a structure to withstand a large earthquake and prevent collapse. The ductility of reinforced ECC was less sensitive to $7 \%$ initial pulses than the ductility of reinforced concrete. Specimens subjected to the $\mathrm{CF}$ deformation history made from both concrete and ECC achieved an ultimate ductility of $12 \%$ drift. When subjected to the C7PF deformation history, the reinforced ECC specimen also achieved $12 \%$ drift, whereas the reinforced concrete specimen reached an ultimate ductility of $7 \%$ drift (a $42 \%$ reduction). The number of complete excursions each specimen sustained was between 54 and 56 except RC-0.95-C7PF, which failed after completing 48 excursions.

Despite sustaining damage through cracking and some crushing and spalling, the core of ECC-0.95-C7PF remained intact due to the relatively high shear strength and damage tolerance of the ECC matrix. The ECC matrix was able to provide sufficient confinement to the steel reinforcement and facilitate failure by bar fracture, the same failure mode as the other reinforced ECC specimen. The extra plastic deformation due to the two $7 \%$ initial pulses was insignificant in contributing to strain accumulation in the reinforcement at the critical section, and did not lead to earlier fracture. In contrast, since both reinforced concrete specimens failed due to concrete crushing, the crushing that occurred early in the deformation history of RC-0.95-C7PF significantly contributed to the cumulative damage that dictated the specimen's ultimate ductility.

Because ultimate ductility of reinforced ECC was less sensitive to deformation history than reinforced concrete specimens, reinforced ECC design for collapse prevention may be more consistent between situations where initial pulses are not expected and situations where initial deformation pulses may be more likely, such as near-fault locations.

\subsection{Impact of deformation history on energy dissipation}

Damage from cracking and plastic deformation of the steel reinforcement contributed to the energy dissipated by each specimen. From the beginning of the test through specimen failure, the energy dissipated by ECC-0.95-C7PF was 93\% of the total energy dissipated by ECC-0.95-CF. In contrast, the difference in normalized energy dissipated per cycle between RC-0.95-CF and RC-0.95-C7PF tended to increase as drift increased beyond $1.1 \%$. Accordingly, hysteresis loops of both reinforced concrete specimens were pinched as drift increased (Figures $4 \mathrm{a}$ and 4b). RC-0.95C7PF dissipated $50 \%$ of the total energy dissipated by RC-0.95-CF from the beginning of the test through each specimen's respective failure.

Energy dissipated per hysteretic cycle can be determined by calculating the area within each hysteretic loop in Figures 4a-d. Energy dissipated by the first cycle at each step was computed and normalized by the area of an equivalent elasto-plastic hysteresis loop per [24] for each specimen. Normalized energy dissipated per cycle by reinforced concrete and reinforced ECC specimens is shown in Figure $5 \mathrm{a}$ and $5 \mathrm{~b}$, respectively. Normalized energy dissipation per cycle is plotted through $4.3 \%$ drift, excluding initial pulses for specimens subjected to the C7PF deformation history.

In both specimens of both materials, normalized energy dissipated per cycle was relatively high at low drifts. As drift increased, normalized energy dissipated decreased until it reached a minimum, then increased again as drift increased.

When comparing reinforced concrete to reinforced ECC specimens subjected to the $\mathrm{CF}$ deformation history, Figures $5 \mathrm{a}$ and $5 \mathrm{~b}$ indicate ECC-0.95-CF absorbed significantly more (normalized) energy per cycle, particularly through $1.6 \%$ drift, than RC-0.95-CF. The increase in normalized energy dissipated per cycle at relatively low drifts is attributed to the increased number of flexural cracks observed in ECC-0.95-CF (Table 5) when compared to RC0.95-CF (Table 4). 

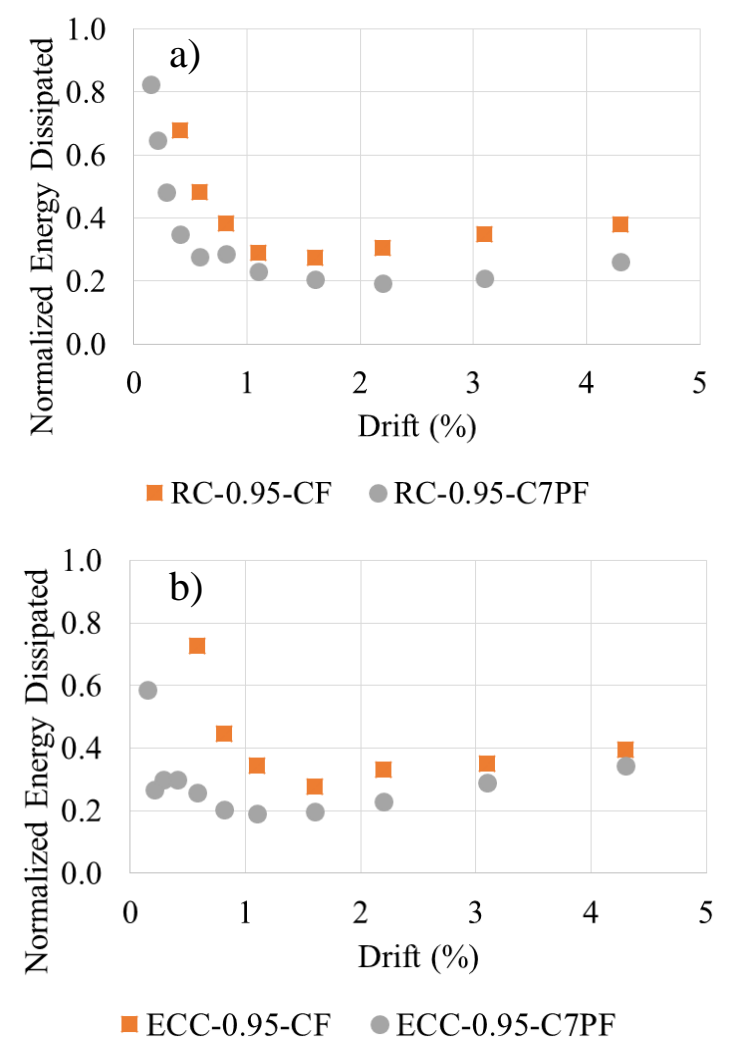

Figure 5: Normalized energy dissipated versus drift per hysteretic cycle by a) reinforced concrete specimens and b) reinforced ECC specimens

Although a similar number of cracks formed in both reinforced ECC specimens, most cracks in ECC-C7PF formed during the initial pulses and did not serve to dissipate energy during steps of $0.15 \%$ drift and beyond. RC-0.95$\mathrm{C} 7 \mathrm{PF}$, however, continued to form cracks beyond the two initial pulses. Thus, when subjected to the C7PF deformation history, the reinforced ECC exhibited a greater reduction in the normalized energy dissipated per cycle at relatively low drifts than reinforced concrete when compared to the CF deformation history.

Up to about $1.6 \%$ drift, normalized energy dissipated per cycle for reinforced concrete was greater than that of reinforced ECC when subjected to the C7PF deformation history. Beyond $1.6 \%$ drift, normalized energy dissipated per cycle by ECC-0.95-C7PF was greater and increased at a higher rate than that of RC-0.95-C7PF. The higher rate of energy dissipation per cycle is believed to be attributed to an increased plastic deformation of the steel reinforcement. Though complete strain gage data was not collected for ECC-0.95-C7PF, residual bond strength in reinforced ECC [15] was expected to engage the steel reinforcement beyond the two initial deformation pulses. In contrast, there was no recorded strain accumulation in RC-95-C7PF beyond the two initial pulses (Figure 3b).

The difference in normalized energy dissipated per cycle between ECC-0.95-CF and ECC-0.95-C7PF reduced as drift increased beyond $1.6 \%$. This follows from the wide hysteresis loops of ECC-0.95-C7PF as drift increased despite the pinching at low drifts following the two initial deformation pulses (Figure 4d).

Results from this study show that energy dissipated by a reinforced ECC component per cycle may be significantly lower during small cycles following initial deformation pulses when compared to cycles of the same amplitude that are part of a monotonically increasing cyclic deformation history. Substantial capacity exists, however, to dissipate energy if large ductility demands are imposed, for example from an aftershock. In a reinforced concrete specimen, large cycles following initial deformation pulses were not nearly as effective in dissipating energy. The ability of a reinforced concrete component to dissipate energy during an aftershock is expected to be more strongly dependent on the deformation history of the main shock, particularly if it contained initial deformation pulses, than a reinforced ECC component.

\section{CONCLUSIONS AND FUTURE WORK}

Two reinforced concrete and two reinforced HPFRCC specimens were tested under two different deformation histories. Differences in cracking, reinforcement strain, hysteretic behavior, ductility, and energy dissipation were observed between cementitious materials and between deformation histories.

When compared to reinforced concrete, the ductility of reinforced ECC specimens was less sensitive to the deformation history applied. Ductility of the reinforced concrete specimen subjected to a deformation history that included two initial pulses to $7 \%$ drift followed by the 
FEMA 461 deformation history was $42 \%$ lower than a nominally identical specimen subjected to the FEMA 461 deformation history without initial deformation pulses. Reinforced ECC specimens achieved the same ultimate ductility when subjected to the same two deformation histories. The high damage tolerance in compression demonstrated by the ECC relative to concrete facilitated the relative indifference between the two deformation histories.

An increased number of cracks and increased plastic deformation of the steel reinforcement in the reinforced ECC relative to the reinforced concrete led to differences in normalized energy dissipated per cycle. Total energy dissipation of reinforced ECC through specimen failure was less sensitive to deformation history than reinforced concrete. Reduction in normalized energy dissipated per cycle due to the deformation history containing two initial deformation pulses was greater in the reinforced ECC specimen at drifts through $1.6 \%$, but greater in the reinforced concrete specimen at drifts beyond $1.6 \%$.

Future work involving reinforced ECC beams with an expanded range of deformation histories, reinforcement ratios, and bar layouts is underway by the authors. The results of this and future related studies inform potential component-level response of reinforced cementitious materials when subjected to a ground motion that induces initial pulse. Data presented herein could be used to develop or calibrate damage indices or plastic hinge models for structural-level analyses involving reinforced ECC structural components.

\section{ACKNOWLEDGEMENTS}

The authors would like to thank the Air Force Institute of Technology and the John A. Blume Earthquake Engineering Center for their generous financial contributions to this research.

\section{REFERENCES}

[1] Maalej, M., and Li, V.C. 1995. Introduction of Strain-Hardening Engineered Cementitious Composites in Design of Reinforced Concrete Flexural
Members for Improved Durability. ACI Structural Journal 92 (2): 167-176.

[2] Douglas, K.S., and Billington, S.L. 2010. Strain Rate Dependence of HPFRCC Cylinders in Monotonic Tension. Materials and Structures 44 (1) (July 6): 391-404.

[3] Kanda, T., and Li, V.C. 1999. New Micromechanics Design Theory for Pseudostrain Hardening Cementitious Composite. Journal of Engineering Mechanics 125 (4): 373-381.

[4] Maalej, M., Li, V.C., and Hashida, T. 1995. Effect of Fiber Rupture on Tensile Properties of Short Fiber Composites. Journal of Engineering Mechanics 121 (8): 903-913.

[5] Mechtcherine, V., Silva, F., Butler, M., Zhu, D., Mobasher, B., Gao, S., and Mäder, E. 2011. Behaviour of StrainHardening Cement-Based Composites Under High Strain Rates. Journal of Advanced Concrete Technology 9 (1): 5162.

[6] Kanda, T., Watanabe, S., and Li, V.C. 1998. Application of Pseudo Strain Hardening Cementitious Composites to Shear Resistant Structural Elements. In Mihashi, H., and Rokugo, K. (Eds) Proc. FRAMCOS-3, Fracture Mechanics of Concrete Structures; 1477-1490.

[7] Li, V.C., and Kanda, T. 1998. Engineered Cementitious Composites for Structural Applications. ASCE J. Materials in Civil Engineering 10 (2): 66-69.

[8] Krawinkler, H. 1996. Cyclic Loading Histories for Seismic Experimentation on Structural Components. Earthquake Spectra 12 (1): 1-12.

[9] Lignos, D.G., Moreno, D.M., and Billington, S.L. 2014. Seismic Retrofit of Steel Moment-Resisting Frames with High-Performance Fiber-Reinforced Concrete Infill Panels: Large-Scale Hybrid Simulation Experiments. Journal of Structural Engineering 140: 1-13.

[10] Frank, T.E., Lepech, M.D., and Billington, S.L. 2015. Effect of Deformation History on Steel-Reinforced HPFRCC Flexural Member Behavior. In Reinhardt, H.W., 
Parra-Montesinos, G.J., and Garrecht, H. (Eds) 7th RILEM Workshop on High Performance Fiber Reinforced Cement Composites (HPFRCC7); 367-374.

[11] Hwang, T.H. 1982. Effects of Variation in Load History on Cyclic Response of Concrete Flexural Members. PhD Thesis. University of Illinois, $231 \mathrm{pp}$.

[12] Kawashima, K., and Koyama, T. 1988. Effect of Number of Loading Cycles on Dynamic Characteristics of Reinforced Concrete Bridge Pier Columns. Structural Eng./Earthquake Eng. 5 (1): 205-213.

[13] Ohno, T., and Nishioka, T. 1984. An Experimental Study on Energy Absorption Capacity of Columns in Reinforced Concrete Structures. Proceedings of the JSCE, Structural Eng./Earthquake Eng. 1 (2): 23-33.

[14] Baker, J.W., and Cornell, C.A. 2008. Vector-Valued Intensity Measures for Pulse-like near-Fault Ground Motions. Engineering Structures 30 (4): 1048-1057.

[15] Bandelt, Matthew J., and Sarah L. Billington. 2014. Monotonic and cyclic bond-slip behavior of ductile highperformance fiber-reinforced cementbased composites. In Schlangan E., Sierra Beltran, M.G., Lukovic, M., and Ye, G. (Eds) Proceedings of the 3d International RILEM Conference on Strain Hardening Cementitious Composites (SHCC3), 1-8.

[16] Moreno, D.M., Trono, W., Jen, G., Ostertag, C., and Billington, S.L. 2014. Tension Stiffening in Reinforced High Performance Fiber Reinforced CementBased Composites. Cement and Concrete Composites 50 (July): 36-46.

[17] Fischer, G., and Li, V.C. 2002. Effect of Matrix Ductility on Deformation Behavior of Steel-Reinforced ECC Flexural Members under Reversed Cyclic Loading Conditions. ACI Structural Journal 99 (6): 781-790.

[18] Yuan, F., Pan, J., Dong, L., and Leung, C.K.Y. 2013. Mechanical Behaviors of Steel Reinforced ECC or ECC/concrete Composite Beams under Reversed Cyclic Loading. Journal of Materials in Civil Engineering: 1-8.
[19] Tavallali, H., Lepage, A., Rautenberg, J., and Pujol, S. Drift Limits of Concrete Frame Members Reinforced with Highperformance Steel Bars and Fibers. In Parra-Montesinos, G., Reinhardt, H., and Naaman, A. (Eds) 6th RILEM Workshop on High Performance Fiber Reinforced Cement Composites (HPFRCC6); 329337.

[20] ACI Committee, American Concrete Institute, and International Organization for Standardization. 2014. Building code requirements for structural concrete (ACI 318-08) and commentary. American Concrete Institute, $520 \mathrm{pp}$.

[21] FEMA 461. 2007. Interim Testing Protocols for Determining the Seismic Performance Characteristics of Structural and Nonstructural Components. 138 pp.

[22] Bandelt, M.J. 2015. Behavior, Modeling, and Impact of Bond in Steel Reinforced High-Performance Fiber-Reinforced Cement-Based Composites. PhD Thesis, Stanford University, $283 \mathrm{pp}$.

[23] Li, V.C. 1997. Damage tolerance of engineered cementitious composites. In Karihloo, B.L, Mai, Y.W., Ripley, M.I., and Ritchie, R.O. (Eds) Advances in Fracture Research, Proc. 9th ICF Conference on Fracture; 619-630.

[24] Lequesne, R.D. 2011. Behavior and Design of High-Performance FiberReinforced Concrete Coupling Beams and Coupled-Wall Systems. PhD Thesis. University of Michigan, 277 pp. 